\title{
Large Animal Models of Ischemic Cardiomyopathy: Are They Enough to Bridge the Translational Gap?
}

\author{
Patricia K. Nguyen, MD, ${ }^{\mathrm{a}, \mathrm{b}, \mathrm{c}}$ and Joseph C. Wu, MD, PhD ${ }^{\mathrm{a}, \mathrm{c}, \mathrm{d}}$ \\ a Stanford Cardiovascular Institute, Stanford University School of Medicine, Stanford, CA \\ ${ }^{b}$ Veterans Administration, Palo Alto, CA \\ c Division of Cardiovascular Medicine, Department of Medicine, Stanford University School of \\ Medicine, Stanford, CA \\ d Department of Radiology, Stanford University School of Medicine, Stanford, CA
}

doi: $10.1007 / \mathrm{s} 12350-015-0078-7$

\section{See related article, pp. 655-665}

Heart failure is a devastating disease with high morbidity and mortality. In 2013, approximately 5.1 million people suffered from chronic heart failure in the United States. ${ }^{1}$ About $50 \%$ of these individuals died within 5 years of their initial diagnosis. ${ }^{1}$ The most common cause of heart failure is coronary artery disease. Unfortunately, treatment options remain limited. Current medical therapy, including angiotensin-converting enzyme (ACE) inhibitors, aldosterone antagonists, and angiotensin and adrenergic receptor blockers, only slow disease progression. The chronic shortage of donor organs restricts the number of heart transplantations performed.

Although novel approaches to cardiac regeneration, such as stem cell and gene therapy, are under investigation, proving efficacy and safety requires extensive preclinical studies before "first in man"' studies can be performed. The success of clinical translation is highly dependent on how well animal models can recapitulate disease in humans and mimic how humans will respond to therapy.

Reprint requests: Patricia Nguyen, MD, Stanford Cardiovascular Institute, Stanford University School of Medicine, 300 Pasteur Drive, Grant Building S140, Stanford, CA 94305-5111; pknguyen@stanford.edu; Joseph C. Wu, MD, PhD, Division of Cardiovascular Medicine, Department of Medicine, Stanford University School of Medicine, 265 Campus Drive G1120B, Stanford, CA 94305-5454; joewu@stanford.edu

J Nucl Cardiol 2015;22:666-72.

$1071-3581 / \$ 34.00$

Copyright (C) 2015 American Society of Nuclear Cardiology.
Modeling heart failure, however, can be challenging because heart failure results from a myriad of causes with distinct clinical features that need to be incorporated into animal models. ${ }^{2}$ Heart failure is also characterized by gradual deterioration of left ventricular (LV) function over a typical span of several years, which has been difficult to incorporate into existing animal models.

Ischemic cardiomyopathy models were first developed in rats. Scientists created surgical models of myocardial infarction by either ligating or occluding the left anterior descending artery (LAD), causing left ventricular dysfunction. Rat models are generally preferable to mice because their larger size facilitates the performance of multimodality imaging, invasive hemodynamics, and histological analysis. ${ }^{3}$ The major advantage of mice, however, is the availability of transgenic and knockout strains and lower housing costs. With the advent of micro-imaging technology at specialized centers, ${ }^{4,5}$ the use of murine heart failure models has become more common albeit with greater expense for imaging. Importantly, the benefits of many of the heart failure therapies to date have first been observed in small animals. Using a rat model of myocardial infarction, for example, Pfeffer et al reported that ACE inhibitors reduced left ventricular (LV) dilatation, increased ejection fraction, and improved survival in rats with moderate to large infarcts. ${ }^{6}$ More recently, the role of calmodulin kinase II (CaMKII) in the causation and progression of cardiac hypertrophy was elucidated in mice. ${ }^{7,8}$ Subsequent studies in large animals and humans have shown that an increased expression of CAMKII in the myocardium is associated with the development of heart failure after myocardial infarction. ${ }^{9,10}$

Demonstration of efficacy and safety in small animal models alone, however, is insufficient for clinical 
translation and regulatory approval because significant differences exist in the physiological characteristics of small animals vs those in humans. Murine hearts, for example, beat over 600 times per minute $(\sim 8-10$ times faster than human heart), which suggests that different mechanisms regulate calcium influxes. ${ }^{3}$ These fundamental differences in physiology can result in mice having a completely opposite response to genetic mutations than humans, as demonstrated in a study by Haghighi et al which showed that while the ablation of gene encoding phospholamban improved murine heart function, hereditary mutation of this protein in humans leads to the development of lethal cardiomyopathy. ${ }^{11}$ The concentration of sarcomeric proteins is also significantly different in murine and human hearts. While alpha myosin heavy chain comprises more than $95 \%$ of the total myofibrillar protein in murine left ventricles, beta myosin heavy chain protein is the major isoform in human hearts, comprising $90 \% .{ }^{11}$ Because myofibril proteins differ in their ATP utilization and contractile force generation, their response to myocardial injury and genetic mutation may not be equal. ${ }^{12}$ Thus, while rodents provide a highthroughput, relatively inexpensive in vivo biological system to study human disease, these models can fall short of recapitulating the pathophysiology of heart failure in humans, and preliminary findings need to be confirmed using large animal models.

Because large animals are physiologically closer to humans, large animal models can potentially bridge the gap between experimental discoveries and clinical applications. Like humans, the heart rates of larger mammals are slower than those of rodents. The left ventricles of larger animals also have similar concentrations of myofibrils. ${ }^{13}$ The most common animals used for large animal models are rabbits, dogs, sheep, and pigs. The most frequent procedures used to induce left ventricular dysfunction include coronary ligation and microembolization, ${ }^{14,15}$ which create permanent macrovascular and microvascular injury, respectively, and coronary balloon catheter occlusion for various durations, which results in ischemia reperfusion injury. ${ }^{16,17}$ The advantages and disadvantages of various large animal models in ischemic cardiomyopathy are detailed in Table 1.

In this edition of the journal, Tarkia et al re-introduce a model of ischemia reperfusion injury that uses a combination of ligation of the distal portion of the LAD followed by proximal occlusion, a model that was previously presented by Teramoto et $\mathrm{al}^{18}$ The reported advantage of this model is the creation of larger myocardial infarctions with acceptable survival rates due to " "preconditioning', effect of distal LAD ligation. Compared to existing models (Table 2), the "new" model successfully creates much larger infarct sizes that result in a larger decrease in ejection fraction. ${ }^{18}$ Not surprisingly, the larger infarct sizes, however, resulted in a much higher mortality rate than observed in other models. ${ }^{14-17,19}$ The question remains whether the benefit of larger infarct size outweighs the significant costs of over $50 \%$ mortality among instrumented animals.

When considering this model as opposed to others, investigators should balance the cost of lower incidence of CHF among instrumented animals against the cost of high mortality that includes costs for housing, noninvasive and invasive procedural, and personnel for animals that ultimately do not undergo randomization. On the other hand, investment in models that closely mimic disease in humans has greater payoffs downstream. A systematic review of animal studies cited in seven leading journals found that only a third of the studies were translated into randomized clinical trials and only a tenth of those were subsequently approved for human patients. ${ }^{20}$ This means that the majority of interventions that showed efficacy in animal models failed to show benefit in humans. Notable examples of these interventions include therapies that were developed to reduce reperfusion injury in myocardial infarction and to protect the brain from additional injury after stroke. ${ }^{21-24}$ More recently, disappointing results from randomized controlled clinical trials using bone marrowderived stem cells for cardiac regeneration provide further support that improved efficacy observed in preclinical models cannot always be replicated in humans. ${ }^{25}$

Perhaps the failure of clinical trials to show benefit noted in animal models speaks more to the need for a more sensitive measure than ejection fraction to evaluate therapeutic efficacy. Because clinical trials are conducted in less controlled settings than animal studies, small changes in ejection fraction may be "washed out" by individual differences in response to treatment or by other experimental variability. In addition to incorporating structural and functional measures to assess heart failure progression, Tarkia et al have introduced the potential of measuring myocardial efficiency to differentiate diseased from normal myocardium. Myocardial efficiency is defined as the ratio of useful work to oxygen consumption. ${ }^{26}$ Efficiency is reduced in heart failure because energy expenditure increases more than myocardial work. Previous studies have shown that poor myocardial efficiency is associated with death, ${ }^{27}$ and efficiency improves with administration of heart failure therapy, ${ }^{28,29}$ suggesting that myocardial efficiency could be a valuable surrogate marker for therapeutic monitoring.

Noninvasive measures of oxygen consumption and myocardial work are promising methods to estimate myocardial efficiency. ${ }^{26}$ To estimate oxygen consumption, Tarkia et al incorporated positron emission tomography (PET) using ${ }^{11} \mathrm{C}$-acetate, which is considered the most accurate noninvasive measure of oxygen 
Table 1. Advantages and disadvantages of different large animal models of ischemic heart failure

\begin{tabular}{|c|c|c|c|}
\hline Model & Procedure types & Advantages & Disadvantages \\
\hline \multirow[t]{3}{*}{ Rabbit } & $\begin{array}{l}\text { Spontaneous myocardial } \\
\text { infarction (Watanabe } \\
\text { heritable hyperlipidemic } \\
\text { rabbits) }\end{array}$ & $\begin{array}{l}\text { Similar electrophysiological } \\
\text { characteristics and } \\
\text { calcium transport }\end{array}$ & $\begin{array}{l}\text { Not always considered a } \\
\text { large animal model }\end{array}$ \\
\hline & Coronary ligation & Transgenic models available & $\begin{array}{l}\text { Unlike humans, left circumflex } \\
\text { is the most dominant artery }\end{array}$ \\
\hline & $\begin{array}{l}\text { Microsphere embolization } \\
\text { Ischemia reperfusion }\end{array}$ & Lower cost & Higher heart rates than humans \\
\hline \multirow[t]{7}{*}{ Dog } & Coronary ligation & $\begin{array}{l}\text { Similar electrophysiological } \\
\text { characteristics and calcium } \\
\text { transport }\end{array}$ & $\begin{array}{l}\text { Significant collateral circulation, } \\
\text { making infarct size variable }\end{array}$ \\
\hline & Microsphere embolization & $\begin{array}{l}\text { Similar ventricular activation } \\
\text { sequence }\end{array}$ & $\begin{array}{l}\text { Coronary anatomy is not similar } \\
\text { to humans, with left coronary } \\
\text { artery dominance }\end{array}$ \\
\hline & Ischemia reperfusion & No left azygous vein like humans & $\begin{array}{l}\text { Ventricular repolarization is } \\
\text { not similar to humans }\end{array}$ \\
\hline & & & Time consuming \\
\hline & & & High cost \\
\hline & & & High risk of arrhythmia and death \\
\hline & & & $\begin{array}{l}\text { Relatively, strict regulatory } \\
\text { guidelines for use }\end{array}$ \\
\hline \multirow[t]{5}{*}{ Sheep } & Coronary ligation & $\begin{array}{l}\text { Scant collateral arteries, resulting } \\
\text { in predictable infarct size }\end{array}$ & $\begin{array}{l}\text { Coronary anatomy is not similar } \\
\text { to humans, with left coronary } \\
\text { artery dominance }\end{array}$ \\
\hline & Microsphere embolization & & $\begin{array}{l}\text { Difficult to perform noninvasive } \\
\text { imaging due to thoracic and } \\
\text { gastrointestinal anatomy }\end{array}$ \\
\hline & Ischemia reperfusion & & High risk of arrhythmia and death \\
\hline & & & High risk of infection \\
\hline & & & Left azygous vein present \\
\hline \multirow[t]{3}{*}{ Pig } & Coronary ligation & $\begin{array}{l}\text { Coronary anatomy and gross } \\
\text { anatomical structure very } \\
\text { close to humans }\end{array}$ & High risk of arrhythmia and death \\
\hline & Microsphere embolization & Similar cardiac output to humans & $\begin{array}{l}\text { Ventricular activation sequence } \\
\text { is different due to location } \\
\text { of Purkinje fibers }\end{array}$ \\
\hline & Ischemia reperfusion & $\begin{array}{l}\text { Scant collateral arteries, resulting } \\
\text { in predictable infarct size }\end{array}$ & Left azygous vein present \\
\hline
\end{tabular}

consumption. ${ }^{30}$ PET imaging of ${ }^{11} \mathrm{C}$-acetate operates on the following principle: After its introduction into the blood stream, acetate is taken up by the myocardium, rapidly converted to acetyl-coenzyme $\mathrm{A}$, oxidized in the tricarobxylic acid (TCA) cycle, and released as ${ }^{11} \mathrm{C}$ carbon dioxide. Because the TCA cycle is tightly coupled with oxidative phosphorylation, myocardial clearance of ${ }^{11} \mathrm{C}$-acetate (as carbon dioxide) can estimate oxygen consumption. However, using a single compartment model to measure myocardial kinetics of ${ }^{11} \mathrm{C}$-acetate turnover, Tarki et al found only a small change in oxygen consumption between control and infarcted animals, which may reflect the dependence of this measure on correct estimates of ${ }^{11} \mathrm{C}$-acetate blood activity and high image quality. ${ }^{26}$ To estimate myocardial work, an assessment of LV structure and function is also required. Tarkia et al used echocardiography and computed tomographic angiography to assess stroke 


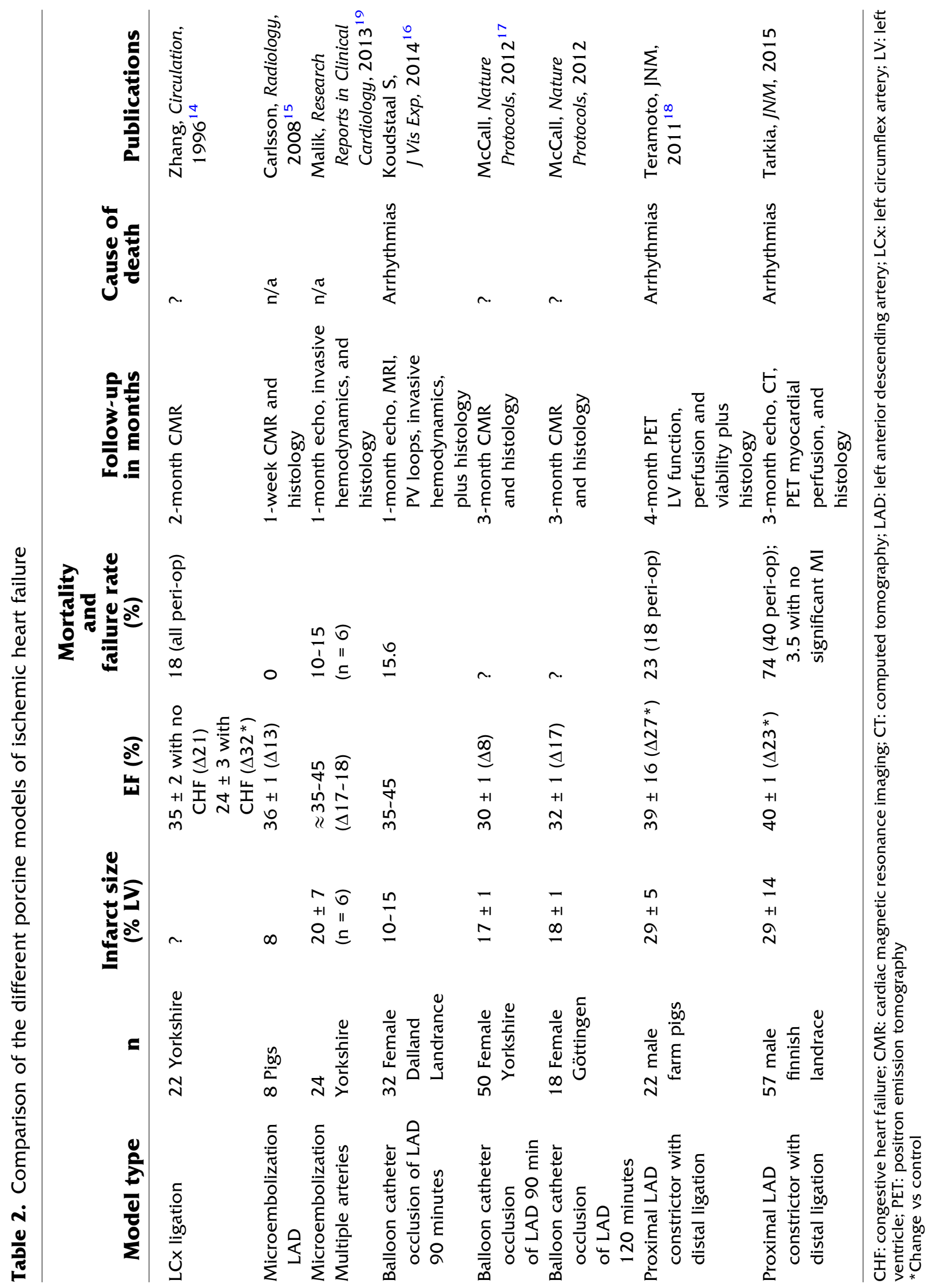




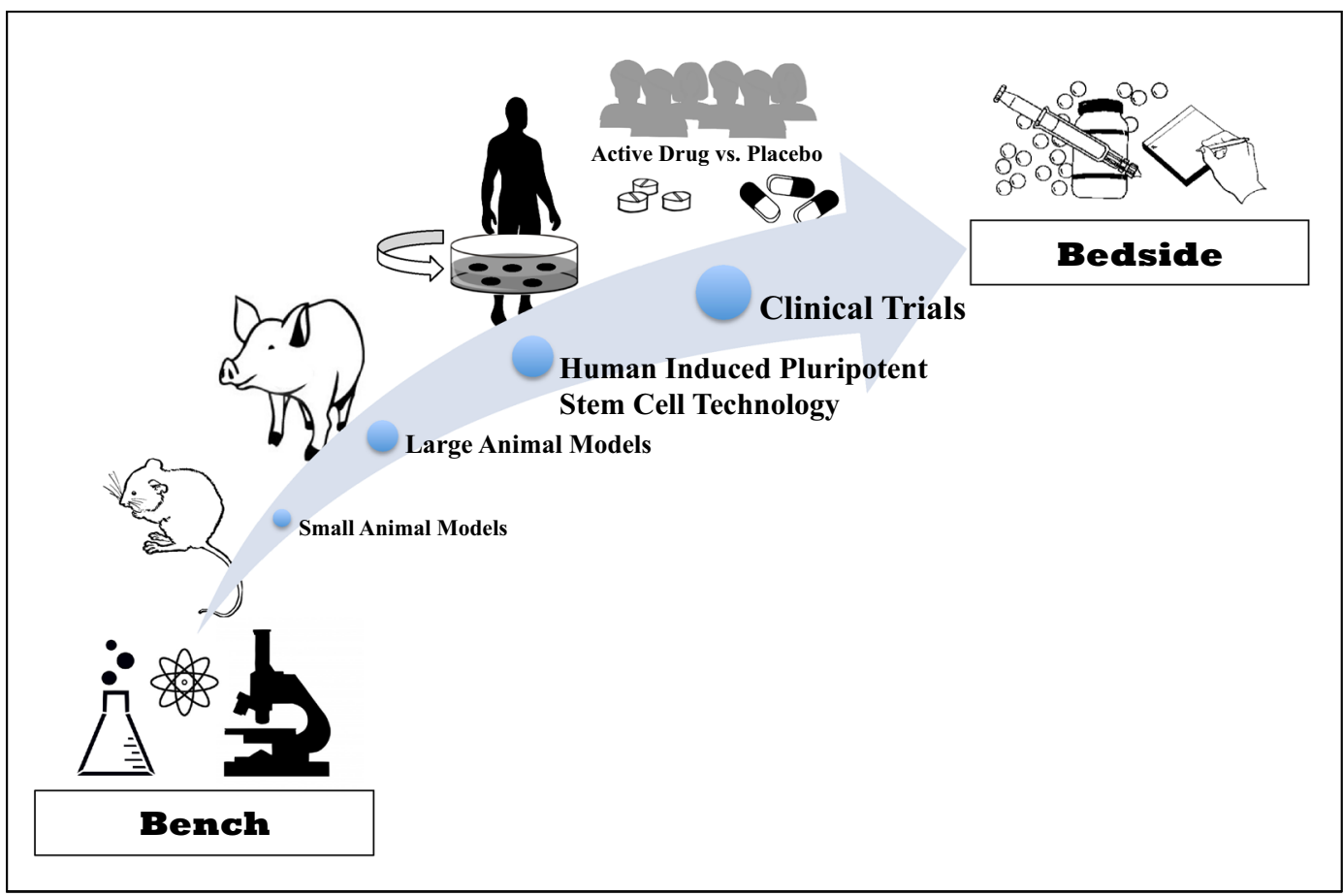

Figure 1. Potential paradigm for the clinical translation of novel heart failure therapy. Although many novel therapies have been shown to be efficacious in small and large animal models, they fail to demonstrate similar efficacy in clinical trials. Because human-induced pluripotent stem cells have been found to recapitulate certain disease processes at the single cell level, they have the potential to close the translational gap between the bench to the bedside.

volume and LV mass, respectively. Although both imaging modalities provide adequate estimation of these parameters, the use of a multimodality approach to measure myocardial efficiency may confound results because hemodynamics may vary among the three imaging approaches.

Cardiac MRI is a promising approach that allows investigators to measure both workload and oxygen consumption sequentially in the same imaging session. Cardiac MRI is already considered the gold standard for the noninvasive evaluation of stroke volume and LV mass. Recently, investigators have successfully used T2based cardiac MR imaging sequences to measure oxygen consumption in large animals and normal volunteers, ${ }^{31,32}$ capitalizing on the relationship between the $\mathrm{T} 2$ blood relaxation rate and the presence of paramagnetic deoxyhemoglobin in red blood cells. Importantly, cardiac MRI can measure ejection fraction, chamber sizes, regional wall motion abnormalities, myocardial perfusion and viability, all of which are important measures of therapeutic efficacy in large animal models. Even with these comprehensive measures to evaluate therapeutic efficacy, however, large animal models may not completely close the translational gap because animals lack identical genotypic and phenotypic characteristics as humans, and thus may not respond exactly the same to physical insults, disease processes, or therapy.

Human-induced pluripotent stem cell (iPSC) technology may facilitate the clinical translation of novel therapies for heart failure (Figure 1). Discovered in 2007 by Shinya Yamanka and James Thompson, ${ }^{33,34}$ human iPSCs are isolated from adult somatic cells including skin, blood, and other tissues, and then "reprogrammed" to their pluripotent state. Human iPSCs can be differentiated to various cell types such as cardiomyocytes and endothelial cells that possess similar morphological, biochemical, electrophysiological, genomic, and mechanical properties as those of primary human cells. ${ }^{35}$ Human iPSC derivatives have been shown to accurately model certain disease processes at the single cell level, making them ideal for evaluating potential therapies prior to Phase I clinical trials. The most extensively studied cardiac diseases modeled by iPSC technology include inherited disorders such as arrhythmic disorders caused by mutations in ion channels (ion chanelopathies) and cardiomyopathies ${ }^{36}$ (e.g., dilated cardiomyopathy, ${ }^{37}$ hypertrophic cardiomyopathy, ${ }^{38}$ and arrhythmogenic right ventricular dysplasia/ cardiomyopathy ${ }^{39}$ ). Using human iPSC technology, 
investigators can conduct a "clinical trial in a dish" before investing in expensive studies in humans, thus eliminating therapies that may be effective in animals but not in humans.

Bringing novel therapies to the clinic for the management of heart failure is an arduous and expensive process with more failures than successes. Improving the efficiency of this process requires the creation of models that most closely replicate human conditions, as well as the incorporation of efficacy measures that reflect meaningful endpoints. It will be important for investigators and regulatory agencies to embrace technological advances such as those discussed here in order to ensure that novel therapies can be delivered expeditiously to patients suffering from heart failure.

\section{Acknowledgments}

We are grateful for the funding support provided by the American Heart Association 10SDG4280129 (PKN), National Institutes of Health U01 HL099776 (JCW), R01 EB009689 (JCW), R01 HL093172 (JCW), California Institute of Regenerative Medicine TR3-05556 and DR2A-05394 (JCW).

\section{Disclosures}

None.

\section{References}

1. Go AS, Mozaffarian D, Roger VL, Benjamin EJ, Berry JD, Borden EJ, et al. Heart disease and stroke statistics-2013 update: A report from the American Heart Association. Circulation 2013;127:e6245.

2. Houser SR, Margulies KB, Murphy AM, et al. Animal models of heart failure: A scientific statement from the American Heart Association. Circ Res 2012;111:131-50.

3. Houser SR, Margulies KB, Murphy AM, Spinale FG, Francis GS, Prabhu SD, et al. Animal models of heart failure: A scientific statement from the American Heart Association. Circ Res 2012;111:131-50.

4. Chen IY, Wu JC. Cardiovascular molecular imaging: Focus on clinical translation. Circulation 2011;123:425-43.

5. Nguyen PK, Lan F, Wang Y, Wu JC. Imaging: Guiding the clinical translation of cardiac stem cell therapy. Circ Re. 2011;109:962-79.

6. Pfeffer JM, Pfeffer MA, Braunwald E. Influence of chronic captopril therapy on the infarcted left ventricle of the rat. Circ Res 1985;57:84-95.

7. Zhang T, Maier LS, Dalton ND, Miyamoto S, Ross J, Bers DM, et al. The deltaC isoform of CMAKII is activated in cardiac hypertrophy and induces dilated cardiomyopathy and heart failure. Circ Res 2003;92:912-9.

8. Zhang R, Khoo MS, Wu Y, Yang Y, Grueter CE, Ni G, et al. Calmodulin kinase II inhibition protects against structural heart disease. Nat Med 2005;11:409-17.

9. Christensen MD, Dun W, Boyden PA, Anderson ME, Mohler PJ, Hund TJ. Oxidized calmodulin kinase II regulates conduction following myocardial infarction: A computational analysis. PLoS Comput Biol 2009;5:e1000583.

10. Sossalla S, Fluschnik N, Schotola H, Ort KR, Neef S, Schulte T, et al. Inhibition of elevated $\mathrm{Ca}^{2+} /$ calmodulin-dependent protein kinase II improves contractility in human failing myocardium. Circ Res 2010;107:1150-61.

11. Haghighi K, Kolokathis F, Pater L, Lynch RA, Asahi M, Gramolini AO, et al. Human phospholamban null results in lethal dilated cardiomyopathy revealing a critical difference between mouse and human. J Clin Invest 2003;111:869-76.

12. Marian AJ. Beta-adrenergic receptors signaling and heart failure in mice, rabbits and humans. J Mol Cell Cardiol 2006;41:11-3.

13. Locher MR, Razumova MV, Stelzer JE, Norman HS, Moss RL. Effects of low-level $\alpha$-myosin heavy chain expression on contractile kinetics in porcine myocardium. Am J Physiol Heart Circ Physiol 2011;300:H869-78.

14. Zhang J, Wilke N, Wang Y, Zhang Y, Wang C, Eijgelshoven MH, et al. Functional and bioenergetic consequences of postinfarction left ventricular remodeling in a new porcine model. Circulation 1996;94:1089-100.

15. Carlsson M, Wilson M, Martin AJ, Saeed M. Myocardial microinfarction after coronary microembolization in swine: MR imaging characterization. Radiology 2009;250:703-13.

16. Koudstaal S, Jansen of Lorkeers S, Gho JM, van Hout GP, Jansen MS, Grundeman PF, et al. Myocardial infarction and functional outcome assessment in pigs. J Vis Exp 2014;86:e51269.

17. McCall FC, Telukuntla KS, Karantalis V, Suncion VY, Heldman AW, Mushtag M, et al. Myocardial infarction and intramyocardial injection models in swine. Nat Protoc 2012;7:1479-96.

18. Teramoto N, Koshino K, Yokoyama I, Miyagawa S, Zeniya T, Hirano Y, et al. Experimental pig model of old myocardial infarction with long survival leading to chronic left ventricular dysfunction and remodeling as evaluated by PET. J Nucl Med 2011;52:761-8.

19. Malik N, Farrell K, Withers S, Wright E, Holt C. A novel porcine model of early left ventricular dysfunction for translational research. Res Rep Clin Cardiol 2013;4:1-7.

20. Hackam DG, Redelmeier DA. Translation of research evidence from animals to humans. JAMA 2006;296:1731-2.

21. Shuaib A, Lees KR, Lyden P, Grotta J, Davalos A, Davis SM, et al. Nxy-059 for the treatment of acute ischemic stroke. N Engl J Med 2007;357:562-71.

22. Dirksen MT, Laarman GJ, Simoons ML, Duncker DJ. Reperfusion injury in humans: A review of clinical trials on reperfusion injury inhibitory strategies. Cardiovasc Res 2007;74:343-55.

23. van der Worp HB, Howells DW, Sena ES, Porritt MJ, Rewell S, O'Collins V, et al. Can animal models of disease reliably inform human studies? PLoS Med 2010;7:e1000245.

24. Yellon DM, Hausenloy DJ. Myocardial reperfusion injury. N Engl J Med 2007;357:1121-35.

25. Nguyen PK, Riegler J, Wu JC. Stem cell imaging: From bench to bedside. Cell Stem Cell 2014;14:431-44.

26. Knaapen P, Germans T, Knuuti J, Paulus WJ, Dijkmans PA, Allaart CP, et al. Myocardial energetics and efficiency: Current status of the noninvasive approach. Circulation 2007;115:918-27.

27. Kim IS, Izawa H, Sobue T, Ishihara H, Somura E, Nishizawa T, et al. Prognostic value of mechanical efficiency in ambulatory patients with idiopathic dilated cardiomyopathy in sinus rhythm. J Am Coll Cardiol 2002;39:1264-8.

28. Eichhorn EJ, Heesch CM, Barnett JH, Alvarez LG, Fass SM, Grayburn PA, et al. Effect of metoprolol on myocardial function and energetics in patients with nonischemic dilated cardiomyopathy: A randomized, double-blind, placebo-controlled study. J Am Coll Cardiol 1994;24:1310-20. 
29. Beanlands RS, Nahmias C, Gordon E, deKemp R, Firnau G, Fallen $\mathrm{E}$, et al. The effects of beta(1)-blockade on oxidative metabolism and the metabolic cost of ventricular work in patients with left ventricular dysfunction: A double-blind, placebo-controlled, positronemission tomography study. Circulation 2000;102:2070-5.

30. Gropler RJ. Noninvasive measurements of myocardial oxygen consumption-can we do better? J Am Coll Cardiol 2003;41:468-70.

31. McCommis KS, He X, Abendschein DR, Gupte PM, Gropler RJ, Zheng J. Cardiac 17o MRI: Toward direct quantification of myocardial oxygen consumption. Magn Reson Med 2010;63:1442-7.

32. Yang Y, Foltz WD, Merchant N, Stainsby JA, Wright GA. Noninvasive quantitative measurement of myocardial and whole-body oxygen consumption using MRI: Initial results. Magn Reson Imaging 2009;27:147-54.

33. Takahashi K, Tanabe K, Ohnuki M, Narita M, Ichisaka T, Tomoda $\mathrm{K}$, et al. Induction of pluripotent stem cells from adult human fibroblasts by defined factors. Cell 2007;131:861-72.

34. Yu J, Vodyanik MA, Smuga-Otto K, Antosiewicz-Bourget J, Frane JL, Tian S, et al. Induced pluripotent stem cell lines derived from human somatic cells. Science 2007;318:1917-20.
35. Burridge PW, Keller G, Gold JD, Wu JC. Production of de novo cardiomyocytes: Human pluripotent stem cell differentiation and direct reprogramming. Cell Stem Cell 2012;10:16-28.

36. Liang P, Lan F, Lee AS, Gong T, Sanchez-Freire V, Wang Y, et al. Drug screening using a library of human induced pluripotent stem cell-derived cardiomyocytes reveals disease-specific patterns of cardiotoxicity. Circulation 2013;127:1677-91.

37. Sun N, Yazawa M, Liu J, Han L, Sanchez-Freire V, Abilez OJ, et al. Patient-specific induced pluripotent stem cells as a model for familial dilated cardiomyopathy. Sci Transl Med 2012;4:130ra147.

38. Lan F, Lee AS, Liang P, Sanchez-Freire V, Nguyen PK, Wang L, et al. Abnormal calcium handling properties underlie familial hypertrophic cardiomyopathy pathology in patient-specific induced pluripotent stem cells. Cell Stem Cell 2013;12:101-13.

39. Matsa E, Burridge PW, Wu JC. Human stem cells for modeling heart disease and for drug discovery. Sci Transl Med 2014;6:239ps236. 